\title{
BG-12 reduces evolution of new enhancing lesions to T1-hypointense lesions in patients with multiple sclerosis
}

\author{
D. G. MacManus • D. H. Miller $\cdot$ L. Kappos $\cdot$ R. Gold $\cdot$ E. Havrdova \\ V. Limmroth - C. H. Polman - K. Schmierer - T. A. Yousry • M. Eraksoy • \\ E. Meluzinova $\cdot$ M. Dufek $\cdot$ M. Yang $\cdot$ G. N. O'Neill $\cdot$ K. Dawson
}

Received: 26 July 2010/Revised: 24 September 2010/Accepted: 24 September 2010/Published online: 21 October 2010

(C) Springer-Verlag 2010

\begin{abstract}
BG-12, an immunomodulatory agent, reduces frequency of new gadolinium-enhancing $(\mathrm{Gd}+)$ lesions in relapsing multiple sclerosis (MS). This study reports the effect of $240 \mathrm{mg}$ BG-12 orally three times daily (tid) for 24 weeks on the evolution of new $\mathrm{Gd}+$ lesions to T1-hypointense lesions. Brain magnetic resonance imaging (MRI) scans from patients in placebo and $240 \mathrm{mg}$ BG-12 tid arms of a phase $2 b$ study were examined
\end{abstract}

Electronic supplementary material The online version of this article (doi:10.1007/s00415-010-5777-z) contains supplementary material, which is available to authorized users.

D. G. MacManus · D. H. Miller $(\bowtie) \cdot$ K. Schmierer .

T. A. Yousry

NMR Research Unit, University College London Institute

of Neurology, Queen Square, London WCIN 3BG, UK

e-mail: d.miller@ion.ucl.ac.uk

\section{K. Schmierer}

Centre for Neuroscience and Trauma (Neuroimmunology

Group), Blizard Institute of Cell and Molecular Science,

Barts and The London Queen Mary School of Medicine

and Dentistry, London E1 1BB, UK

\section{Kappos}

Department of Neurology, University Hospital Basel,

Petersgraben 4, 4031 Basel, Switzerland

R. Gold

University Clinic Bochum at St. Josef Hospital,

Gudrunstr. 56, 44791 Bochum, Germany

E. Havrdova

Charles University in Prague, First Faculty of Medicine,

Kateřinská 32, 12108 Prague 2, Czech Republic

V. Limmroth

Cologne City Hospitals, University of Cologne, Ostmerheimer

Str. 200, 51109 Cologne, Germany retrospectively. Included patients had at least one new $\mathrm{Gd}+$ lesion from weeks 4 to 12 . Week 24 scans were analyzed for number and proportion of new $\mathrm{Gd}+$ lesions that evolved to T1-hypointense lesions. Eighteen patients receiving BG-12 and 38 patients receiving placebo were included in the analysis. The analysis tracked 147 new $\mathrm{Gd}+$ lesions in patients from the BG-12 group and 221 $\mathrm{Gd}+$ lesions in patients from the placebo group. The percentage of $\mathrm{Gd}+$ lesions that evolved to T1-hypointense lesions was $34 \%$ lower with BG-12 treatment versus placebo (29\%, BG-12; 44\%, placebo; odds ratio $0.51 ; 95 \%$ confidence interval $0.43,0.61 ; p<0.0001)$. In addition to

\section{H. Polman \\ VU Medical Centre, P. O. Box 7057, \\ 1007 MB Amsterdam, The Netherlands}

M. Eraksoy

Department of Neurology, Istanbul Faculty of Medicine,

Istanbul University, Capa, Istanbul, Turkey

\section{E. Meluzinova}

Department of Neurology,

2nd Medical School of Charles University,

Motol University Hospital, Prague, Czech Republic

M. Dufek

Masaryk University, Žerotínovo nám. 617/9,

60177 Brno, Czech Republic

M. Yang · G. N. O’Neill · K. Dawson

Biogen Idec, Inc, 14 Cambridge Center,

Cambridge, MA 02142, USA 
reducing frequency of new Gd+ lesions, BG-12 significantly reduced probability of their evolution to T1-hypointense lesions in patients with MS compared with placebo.

Keywords Clinical trial - Multiple sclerosis - MRI · Dimethyl fumarate $\cdot$ BG-12 $\cdot$ Hypointense lesions

\section{Introduction}

BG-12 is an oral formulation of dimethyl fumarate (DMF) currently in clinical development for relapsing forms of multiple sclerosis (MS). Preclinical studies using in vitro cell cultures and in vivo experimental autoimmune encephalomyelitis models have demonstrated anti-inflammatory and neuroprotective effects of DMF and its primary metabolite, monomethyl fumarate [1, 2]. DMF and monomethyl fumarate activate the nuclear factor erythroid-2-related factor (Nrf2) transcriptional pathway [3], which is central to oxidative and metabolic stress response, essential for immune homeostasis, and implicated as a regulator of myelin maintenance in the central nervous system [4-7].

In a double-blind, dose-ranging, phase $2 \mathrm{~b}$ study of BG12 in patients with relapsing MS, 257 patients were randomized to receive BG-12 at rates of $120 \mathrm{mg}$ once daily (qd), $120 \mathrm{mg}$ three times daily (tid; $360 \mathrm{mg} /$ day), $240 \mathrm{mg}$ tid $(720 \mathrm{mg} /$ day $)$, or placebo for 24 weeks during an initial placebo-controlled treatment period [8]. Treatment with $240 \mathrm{mg}$ BG-12 tid resulted in a $69 \%$ reduction in total mean number of new gadolinium-enhancing $(\mathrm{Gd}+)$ lesions on MRI scans from weeks 12 to 24 compared with placebo (4.5, BG-12; 1.4, placebo; $p<0.001)$. BG-12 at $240 \mathrm{mg}$ tid also reduced the number of new/enlarging T2-hyperintense lesions by $48 \%(p<0.001)$ and new T1-hypointense lesions by 53\% $(p=0.014)$ compared with placebo. This greater effect on T1-hypointense lesions versus T2-hyperintense lesions is unusual because disease-modifying therapies typically have a greater impact on T2-hyperintense lesions; thus, further investigation was warranted.

Some, but not all, Gd+ lesions evolve to persistent T1-hypointense lesions seen on T1-weighted spin echo images [9]. The presence of persistent nonenhancing T1-hypointense lesions on brain magnetic resonance imaging (MRI) scans of patients with MS is considered a putative marker for myelin and axonal damage [10]. In this retrospective analysis of the phase $2 b$ study, we investigate whether BG-12 affected the evolution of new $\mathrm{Gd}+$ lesions to persistent T1-hypointense lesions in patients with relapsing MS.

\section{Patients and methods}

Patients and study design

The 240 mg BG-12 tid group was the only BG-12 treatment group included in this retrospective analysis because it was the BG-12 study arm that showed significant and greatest reduction in $\mathrm{Gd}+$ lesions, T2-hyperintense lesions, and T1-hypointense lesions compared with placebo. Full study methods have been published elsewhere [8]. Briefly, this double-blind, parallel-group, dose-ranging phase $2 b$ study of BG-12 enrolled 257 patients from 43 centers in the Czech Republic, Germany, Hungary, the Netherlands, Poland, Russia, Sweden, Switzerland, Turkey, and the United Kingdom. During an initial placebo-controlled treatment period, patients were equally randomized to receive BG-12 at $120 \mathrm{mg}$ qd, $120 \mathrm{mg}$ tid, $240 \mathrm{mg}$ tid, or placebo for 24 weeks. Key inclusion criteria were patient age between 18 and 55 years (inclusive); a diagnosis of relapsing-remitting MS according to the McDonald criteria (nos. 1-4) [11]; a baseline Expanded Disability Status Scale score between 0.0 and 5.0 (inclusive) [12]; and at least one relapse within 12 months before randomization and a brain MRI consistent with MS, or Gd+ lesions on MRI performed within 6 weeks of randomization. Patients were excluded if they received mitoxantrone or cyclophosphamide within 1 year; cyclosporine, azathioprine, methotrexate, natalizumab, intravenous immunoglobulin, plasmapheresis, or other investigational drugs within 6 months; glatiramer acetate or interferon beta within 3 months; or corticosteroids (oral or intravenous), 4-aminopyridine, or related products within 30 days of randomization.

\section{Standard protocol approvals and registrations}

The study protocol was approved by independent ethics committees, and the study was conducted in accordance with the Declaration of Helsinki, International Conference of Harmonisation and Good Clinical Practice guidelines, and local regulations. Informed consent was provided by all patients enrolled in the study. The study was registered on ClinicalTrials.gov (identifier NCT00168701).

MRI acquisition protocol and analysis

Brain MRI scans were obtained at baseline and weeks 4, 8 , $12,16,20$, and 24 using a system operating at 1.0 or 1.5 tesla. A dual-echo fast spin echo sequence (repetition time $=2,500-3,300 \mathrm{~ms} ;$ short echo time $=10-40 \mathrm{~ms}$; long echo time $=80-100 \mathrm{~ms}$ ) was used to obtain proton density and T2-weighted images. A conventional spin echo 
sequence (repetition time $=500-700 \mathrm{~ms}$; echo time $=$ 10-20 ms) was applied for obtaining T1-weighted images (before and after the injection of $0.1 \mathrm{mmol} / \mathrm{kg}$ gadolinium contrast medium) in the corresponding spatial location to the fast spin echo scans. For all MRI sequences, 46 contiguous $3 \mathrm{~mm}$ thick axial slices were acquired using a field view of $250 \mathrm{~mm}$, a reconstructed image matrix of $256 \times$ 256 , and an in-plane spatial resolution of $0.97 \times 0.97 \mathrm{~mm}$.

\section{MRI analysis}

After completion of the clinical study, a retrospective analysis was performed using MRI scans obtained from patients assigned to the $240 \mathrm{mg}$ BG-12 tid and placebo groups in the phase $2 \mathrm{~b}$ study. Examination of all scans was performed by personnel (DGM, KS, TAY) blinded to the patients' treatment group assignment and clinical details. Lesions were analyzed by visual inspection of all scans using electronic data where available and hard copy images where satisfactory electronic data were not available. All new $\mathrm{Gd}+$ lesions were identified on scans from weeks 4,8 , and 12 . To confirm that the new $\mathrm{Gd}+$ lesions also were de novo T2 lesions, the prior MRI scan was reviewed. Regions of new gadolinium enhancement in pre-existing T2 lesions were not included in the analysis because there already may have been tissue damage, which would influence the likelihood of subsequent $\mathrm{T} 1$ hypointensity in these regions. Gd+ lesions were classified as large $(>5 \mathrm{~mm})$ or small $(\leq 5 \mathrm{~mm})$ based on measurement of their largest diameter. This cutoff criterion ( $>5 \mathrm{~mm}$ and $\leq 5 \mathrm{~mm}$ ) was chosen for this analysis because it was used in similar analyses for other MS therapeutics [13, 14]. The status of the new Gd+ lesions was evaluated on postcontrast T1-weighted scans obtained at week 24 and reported as still $\mathrm{Gd}+$ or no longer enhancing. Nonenhancing lesions were further classified as T1-isointense lesions or T1hypointense lesions relative to the surrounding normalappearing white matter. The size of the nonenhancing lesions $(>5 \mathrm{~mm}$ or $\leq 5 \mathrm{~mm}$ ) also was recorded.

\section{Statistical analysis}

Patients in the placebo and $240 \mathrm{mg}$ BG-12 tid arms who had at least one $\mathrm{Gd}+$ lesion from weeks 4 to 12 were included in the analysis. For each patient, the following were calculated: cumulative number of new $\mathrm{Gd}+$ lesions on MRI scans from weeks 4 to 12 , cumulative number of T1-hypointense lesions that formed from the $\mathrm{Gd}+$ lesions at week 24, and proportion of $\mathrm{Gd}+$ lesions from weeks 4 to 12 that evolved to T1-hypointense lesions at week 24. For each treatment group, the following were calculated: total number of new $\mathrm{Gd}+$ lesions from weeks 4 to 12 , total number and proportion of $\mathrm{Gd}+$ lesions that evolved to T1-hypointense lesions at week 24, and number and proportion of large $(>5 \mathrm{~mm})$ and small $(\leq 5 \mathrm{~mm}) \mathrm{Gd}+$ lesions and T1-hypointense lesions. Summary statistics were used to describe these data.

At the lesion level, a logistic regression model based on generalized estimating equations which take into account within-patient correlation of lesions, was used to analyze and compare the probability of evolution from a new $\mathrm{Gd}+$ lesion to a T1-hypointense lesion between the BG-12 and placebo groups. For the primary analysis, the model was adjusted for baseline number of $\mathrm{Gd}+$ lesions. In additional analyses, the model was adjusted for baseline number of $\mathrm{Gd}+$ lesions, years since disease onset, and relapses in the previous 3 years, or baseline number of $\mathrm{Gd}+$ lesions, years since diagnosis, and number of relapses in the previous 3 years as categorical variables. The odds ratio (OR) of lesion evolution from $\mathrm{Gd}+$ to $\mathrm{T} 1$-hypointense was computed using the placebo group as a reference.

\section{Results}

The 24 week, placebo-controlled period of the BG-12 phase $2 \mathrm{~b}$ clinical study included 65 patients in the placebo group and 63 patients in the BG-12 $240 \mathrm{mg}$ tid group. Of these, twice as many patients in the placebo group $(n=38)$ than in the BG-12 group $(n=18)$ had one or more $\mathrm{Gd}+$ lesion at weeks 4-12 and were included in the retrospective analysis. The demographic and baseline patient characteristics of the present study cohort were similar to those of the entire study population (Table 1) [8]. At baseline, the mean number of $\mathrm{Gd}+$ lesions was slightly higher in the BG-12 group (3.3 in 18 patients) compared with placebo (2.7 in 38 patients) ( $p=$ not significant). Because we selected patients who had one or more $\mathrm{Gd}+$ lesions from weeks 4 to 12 , it was not surprising that the mean number of baseline $\mathrm{Gd}+$ lesions in the present retrospective analysis cohort was slightly higher than that for the entire phase $2 \mathrm{~b}$ study population in the placebo (2.7 in the present analysis vs. 1.6 in the entire phase $2 \mathrm{~b}$ study population) and BG-12 (3.3 in the present analysis vs. 1.3 in the entire phase $2 b$ study population) groups.

When analyzing these data at the patient level (i.e., proportion of $\mathrm{Gd}+$ lesions that converted to T1-hypointense lesions was calculated for each patient and summary statistics for both treatment groups were tallied), the 18 patients in the BG-12 group had a higher mean number of $\mathrm{Gd}+$ lesions (8.2) than the 38 patients in the placebo group (5.8) on scans at weeks 4, 8, and 12 (Table 2). However, the mean number of T1-hypointense lesions formed from the $\mathrm{Gd}+$ lesions by week 24 was similar in the BG-12 and placebo groups $(2.3$, BG-12; 2.6, placebo) ( $p=$ not significant). This result is due to the fact that the mean proportion of $\mathrm{Gd}+$ lesions that evolved to T1-hypointense 
Table 1 Demographic and baseline patient characteristics

\begin{tabular}{|c|c|c|}
\hline & Placebo $(n=38)$ & $240 \mathrm{mg} \mathrm{BG}-12$ tid $(n=18)$ \\
\hline \multicolumn{3}{|l|}{ Age, years } \\
\hline Mean & 34.9 & 33.4 \\
\hline Median & 35.0 & 30.0 \\
\hline Range & $21-49$ & $18-51$ \\
\hline \multicolumn{3}{|c|}{ Gender, $n(\%)$} \\
\hline Male & $14(37)$ & 7 (39) \\
\hline Female & $24(63)$ & $11(61)$ \\
\hline \multicolumn{3}{|l|}{ EDSS score } \\
\hline Mean & 2.5 & 3.0 \\
\hline Range & $0-5$ & $1-5$ \\
\hline \multicolumn{3}{|c|}{ Time since disease onset, years } \\
\hline Mean & 8.0 & 8.5 \\
\hline Median & 6.0 & 7.5 \\
\hline Range & $1-28$ & $1-23$ \\
\hline \multicolumn{3}{|c|}{ Time since diagnosis, years } \\
\hline Mean & 5.1 & 4.1 \\
\hline Median & 4.0 & 3.0 \\
\hline Range & $0-26$ & $0-9$ \\
\hline \multicolumn{3}{|c|}{ No. of relapses } \\
\hline \multicolumn{3}{|l|}{ Prior year } \\
\hline Mean & 1.3 & 1.4 \\
\hline Median & 1.0 & 1.0 \\
\hline Range & $0-3$ & $1-2$ \\
\hline \multicolumn{3}{|c|}{ Prior 3 years } \\
\hline Mean & 2.4 & 3.2 \\
\hline Median & 2.0 & 3.0 \\
\hline Range & $1-5$ & $1-7$ \\
\hline \multicolumn{3}{|c|}{ No. of Gd + lesions at baseline } \\
\hline Mean & 2.7 & 3.3 \\
\hline Median & 1.0 & 1.0 \\
\hline Range & $0-53$ & $0-19$ \\
\hline
\end{tabular}

tid three times daily, EDSS Expanded Disability Status Scale, $G d+$ gadolinium enhancing

lesions per patient was 0.29 in the BG-12 group compared with 0.41 in the placebo group; this outcome represents a $29 \%$ reduction in evolved $\mathrm{Gd}+$ lesions with BG-12 treatment when analyzing lesions at the patient level.

When analyzing these data at the lesion level (i.e., each lesion is counted as one observation in the analysis), 147 new Gd+ lesions from the 18 patients in the BG-12 group and $221 \mathrm{Gd}+$ lesions from the 38 patients in the placebo group were tracked on scans from weeks 4 through 12 and analyzed at week 24 to see if they had evolved into a T1 hypointensity (Fig. 1; Table 2). The proportion of total $\mathrm{Gd}+$ lesions that evolved to T1-hypointense lesions was 0.29 in the BG-12 group versus 0.44 in the placebo group (Fig. 1; Table 2); this result represents a $34 \%$ reduction when analyzing data at the lesion level with BG-12 treatment compared with placebo. The OR for the evolution of new $\mathrm{Gd}+$ lesions to T1-hypointense lesions for BG12 compared with placebo was 0.51 (95\% confidence interval $[\mathrm{CI}] 0.43,0.61 ; p<0.0001)$. When the model was adjusted for years since disease onset and relapses in the previous 3 years in addition to baseline $\mathrm{Gd}+$ lesions, the OR was 0.40 (95\% CI $0.25,0.66 ; p=0.0003$ ). Similarly, when the model was adjusted for years since diagnosis and relapses in the previous 3 years in addition to baseline $\mathrm{Gd}+$ lesions, the OR was 0.49 (95\% CI 0.27, 0.88; $p=0.0171$ ). Exclusion of three patients (two from the placebo group and one from the BG-12 group) who had relatively large numbers $(\geq 40)$ of $\mathrm{Gd}+$ lesions from the analysis did not influence this result (OR $0.65 ; 95 \%$ CI $0.47,0.89$; $p=0.008$ ).

When analyzing these data by lesion size, $40(27 \%)$ of the Gd+ lesions in the BG-12 group and $76(34 \%)$ of the $\mathrm{Gd}+$ lesions in the placebo group were classified as large $(>5 \mathrm{~mm})$ on the basis of lesion diameter (Fig. 1). In placebo-treated patients, the probability of large $\mathrm{Gd}+$ lesions becoming $\mathrm{T} 1$ hypointense was higher than that for small $\mathrm{Gd}+$ lesions $(\leq 5 \mathrm{~mm})(48 / 76$ [0.63] vs. 50/145 [0.34]) (Table 2). In BG-12-treated patients, large Gd+ lesions also were more likely to become $\mathrm{T} 1$ hypointense than were small Gd+ lesions (21/40 [0.52] vs. 21/107 [0.20]). There was a trend for fewer large $\mathrm{Gd}+$ lesions to evolve to T1-hypointense lesions in the BG-12 treatment arm compared with placebo (OR $0.62 ; 95 \%$ CI $0.39,1.01$; $p=0.055)$. The probability of small $\mathrm{Gd}+$ lesions evolving to T1-hypointense lesions was significantly lower with BG-12 treatment compared with placebo (OR 0.37; 95\% CI $0.30,0.45 ; p<0.0001)$. Overall, the proportion of large T1-hypointense lesions that evolved from any $\mathrm{Gd}+$ lesions (large or small) was not different in the BG-12-treated group (10\%) compared with the placebo group (15\%) $(p=0.251)$.

\section{Discussion}

In this retrospective analysis of a phase $2 \mathrm{~b}$ study, treatment with $240 \mathrm{mg}$ BG-12 tid orally for 24 weeks reduced the probability of evolution of new $\mathrm{Gd}+$ lesions to T1-hypointense lesions compared with placebo in patients with relapsing MS (OR 0.51; 95\% CI 0.43, 0.61; $p<0.0001$ ). Even when the model was adjusted for additional baseline factors, including disease duration and relapse activity in the previous 3 years, the difference between the BG- 12 and placebo groups remained significant $(p=0.0171)$.

A potential mechanism for reduced evolution from $\mathrm{Gd}+$ to $\mathrm{T} 1$ hypointensity is a reduction in the size of $\mathrm{Gd}+$ lesions because larger $\mathrm{Gd}+$ lesions are more likely to become $\mathrm{T} 1$ hypointense (as seen in the placebo arm of the 
Table 2 Number of new Gd+ lesions on scans from weeks 4 to 12 and number and proportion evolving to T1-hypointense lesions at week 24

\begin{tabular}{|c|c|c|}
\hline & $\begin{array}{l}\text { Placebo } \\
(n=38)\end{array}$ & $\begin{array}{l}240 \mathrm{mg} \mathrm{BG}-12 \\
\text { tid }(n=18)\end{array}$ \\
\hline \multicolumn{3}{|l|}{ Patient level } \\
\hline \multicolumn{3}{|l|}{ No. of new $\mathrm{Gd}+$ lesions per patient on scans from weeks 4 to 12} \\
\hline Mean (SD) & $5.80(9.50)$ & $8.20(13.35)$ \\
\hline Median & 3.0 & 4.0 \\
\hline Range & $1-45$ & $1-59$ \\
\hline \multicolumn{3}{|l|}{ No. of T1-hypointense lesions at week $24, n(\%)$} \\
\hline 0 & $12(32)$ & $5(28)$ \\
\hline 1 & $10(26)$ & $7(39)$ \\
\hline 2 & $5(13)$ & $1(6)$ \\
\hline$\geq 3$ & $11(29)$ & $5(28)$ \\
\hline Mean (SD) & $2.60(4.91)$ & $2.30(3.97)$ \\
\hline Proportion of Gd+ lesions per patient evolved to T1-hypointense lesions at week 24, mean (SD) & $0.41(0.37)$ & $0.29(0.30)$ \\
\hline \multicolumn{3}{|l|}{ Lesion level } \\
\hline No. of T1-hypointense le sions on scan from week 24 & 98 & 42 \\
\hline No. of $\mathrm{Gd}+$ lesions on scans from weeks 4 to 12 & 221 & 147 \\
\hline Proportion of Gd+ lesions evolved to T1-hypointense lesions at week 24 & 0.44 & 0.29 \\
\hline $\begin{array}{l}\text { Odds ratio for probability of evolution from Gd+ lesions to T1-hypointense lesions } \\
(95 \% \mathrm{CI}), \mathrm{BG}-12 \text { vs. placebo }\end{array}$ & \multicolumn{2}{|c|}{$\begin{array}{l}0.51(0.43,0.61) \\
\quad p<0.0001\end{array}$} \\
\hline No. of T1-hypointense lesions on scan from week 24 & 48 & 21 \\
\hline No. of large Gd+ lesions on scans from weeks 4 to 12 & $\overline{76}$ & $\overline{40}$ \\
\hline Proportion of large $\mathrm{Gd}+$ lesions evolved to T1-hypointense lesions at week 24 & 0.63 & 0.52 \\
\hline $\begin{array}{l}\text { Odds ratio for probability of evolution from large } \mathrm{Gd}+\text { lesions to T1-hypointense } \\
\text { lesions }(95 \% \mathrm{CI}), \mathrm{BG}-12 \text { vs. placebo }{ }^{\mathrm{a}}\end{array}$ & \multicolumn{2}{|c|}{$\begin{array}{l}0.62(0.39,1.01) \\
\quad p=0.055\end{array}$} \\
\hline No. of T1-hypointense lesions on scan from week 24 & $\underline{50}$ & 21 \\
\hline No. of small Gd+ lesions on scans from weeks 4 to 12 & $\overline{145}$ & 107 \\
\hline Proportion of small Gd+ lesions evolved to T1-hypointense lesions at week 24 & 0.34 & 0.20 \\
\hline $\begin{array}{l}\text { Odds ratio for probability of evolution from small Gd+ lesions to T1-hypointense } \\
\text { lesions }(95 \% \mathrm{CI}), \mathrm{BG}-12 \text { vs. placebo }\end{array}$ & \multicolumn{2}{|c|}{$\begin{array}{l}0.37(0.30,0.45) \\
\quad p<0.0001\end{array}$} \\
\hline
\end{tabular}

a Analysis was performed using a logistic regression model based on the generalized estimating equation which takes into account within-patient correlation of the lesions, and adjusted for baseline number of $\mathrm{Gd}+$ lesions

$G d+$ gadolinium enhancing, tid three times daily, $S D$ standard deviation, $C I$ confidence interval

present study and in a previous study [13]). Although the proportion of large Gd+ lesions was slightly lower in BG12-treated versus placebo-treated patients (27 vs. $34 \%$ ), this mechanism does not explain the reduced conversion to T1 hypointensity, which was evident for small and large $\mathrm{Gd}+$ lesions, though more so for small lesions $(63 \%$ reduction in odds of lesion evolution for small $\mathrm{Gd}+$ lesions $[p<0.001]$ vs. $38 \%$ reduction for large lesions $[p=0.055])$.

The development of new $\mathrm{Gd}+$ lesions on T1-weighted MRI indicates blood-brain barrier breakdown and suggests active inflammation at the site of enhancement [15]. Most new $\mathrm{Gd}+$ lesions are hypointense on unenhanced T1-weighted images during the acute phase, but many of these lesions become T1 isointense during follow-up [9]; most remain visible as high-signal lesions on T2-weighted images. Histopathological studies have shown that persistent T1-hypointense lesions are less likely to remyelinate [16] and are associated with greater tissue matrix damage, including axonal loss, compared with T1-isointense lesions $[10,17,18]$. Thus, therapeutic agents that limit the evolution of new $\mathrm{Gd}+$ lesions to T1-hypointense lesions are likely to confer benefit to patients with MS by reducing the extent of axonal damage at the lesion site. Similar to BG-12, some currently approved MS disease-modifying therapies affect the evolution of $\mathrm{Gd}+$ lesions to T1-hypointense lesions [14, 19]. In patients treated with natalizumab, the proportion of $\mathrm{Gd}+$ lesions that evolved to T1-hypointense lesions was $15 \%$ (vs. $25 \%$ in the placebo group, $p=0.045$ ) and the OR of evolution from $\mathrm{Gd}+$ to $\mathrm{T} 1$-hypointense lesions was $0.48(95 \% \mathrm{CI}$ $0.24,0.94 ; p=0.031$ ) [14]. Glatiramer acetate has also been shown to reduce the evolution of $\mathrm{Gd}+$ lesions to T1-hypointense lesions compared with placebo (16\% vs. 


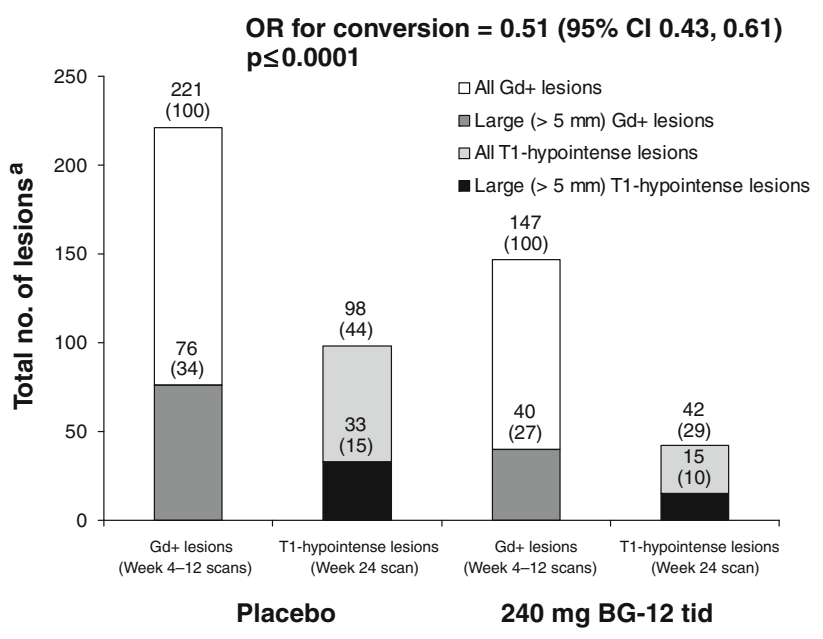

Fig. 1 Effect of BG-12 on evolution of gadolinium-enhancing $(\mathrm{Gd}+)$ lesions to T1-hypointense lesions. Total numbers of $\mathrm{Gd}+$ lesions from weeks 4 to 12 and the number of T1-hypointense lesions formed from the $\mathrm{Gd}+$ lesions at week 24 are shown. The numbers of large $(>5 \mathrm{~mm}) \mathrm{Gd}+$ and large T1-hypointense lesions also are shown. ${ }^{a}$ Numbers in parentheses indicate percentage of total Gd+ lesions on scans from weeks 4 to 12 (e.g., in placebo-treated patients, 76/ $221=34 \%, 98 / 221=44 \%$, and $33 / 221=15 \%$ ). $C I$ confidence interval; $O R$ odds ratio

$31 \%, p=0.002)$ [19]. Although one study showed no such effect for interferon beta-1b versus placebo [13], a recent study reported fewer $\mathrm{Gd}+$ lesions evolving to T1-hypointense lesions with interferon beta-1b compared with glatiramer acetate [20].

Anti-inflammatory effects of oral fumarates have been demonstrated in preclinical and clinical studies $[1,21]$ and were the initial reason for the development of BG-12 as a therapeutic agent in MS [1]. BG-12 can activate the Nrf2 transcriptional pathway in cultured cells [3]. The Nrf2 pathway is known to be a critical regulator of oxidative and metabolic stress response, and activation of this pathway confers neuroprotective effects. Specifically, scientific evidence suggests that Nrf2 mediates its protective effects by increasing the transcription of genes coding for detoxification enzymes and improving neuronal survival [22-24], maintaining the integrity of myelin [7], and protecting the blood-brain barrier [25].

A recent analysis evaluated the feasibility of using the evolution of contrast-enhancing lesions to T1-hypointense lesions as a marker of protection against subsequent axonal loss of treatment. The authors concluded that 200 patients per treatment arm would be required to detect a treatment effect of 50\% [26]. Given these results, our analysis may be underpowered to detect a treatment effect; however, the greater effect of $240 \mathrm{mg}$ BG-12 tid on T1-hypointense lesions compared with $\mathrm{T} 2$-hyperintense lesions observed in the overall phase $2 b$ study supports the results of the present retrospective analysis and warrants further investigation.

Taken together, the primary results from the phase $2 b$ study of BG-12 in patients with relapsing MS and the results of the retrospective analysis presented here provide evidence suggesting both an anti-inflammatory effect (reduced number of Gd+ lesions) and reduced axonal loss in post-inflammatory lesions (fewer $\mathrm{Gd}+$ lesions becoming T1-hypointense). The reduced evolution of T1-hypointense lesions from $\mathrm{Gd}+$ lesions was observed over a relatively short (i.e., 6 months) treatment period, and future longerterm studies will help to better understand the significance of these preliminary findings and their implications with regard to protection from axonal damage.

Acknowledgments The authors acknowledge the contributions of Hema Gowda and Matthew Hasson, Scientific Connexions, Newtown, PA, USA, for technical and editorial assistance in preparing this manuscript for submission. Their work was funded by Biogen Idec, Inc. The authors also acknowledge the role of Virginia Santana with respect to MRI data management. Ludwig Kappos is supported by the Swiss MS Society. Eva Havrdova is supported by the Czech Ministry of Education (Research Program MSM 0021620849). This study was supported by Biogen Idec. Funding was received from the UK Department of Health's National Institute for Health Research Biomedical Research Center's funding scheme (UCLH/UCL Comprehensive Biomedical Research Trust). The NMR Research Unit at the UCL Institute of Neurology is supported by the MS Society of Great Britain and Northern Ireland. Statistical analyses were conducted by M. Yang, MS, Biogen Idec, Cambridge, MA. Please see online resource 1 for a list of BG-12 Phase 2b Study Investigators.

Conflict of interest D.G. MacManus declares no conflicts of interest. D.H. Miller has received honoraria through payments to his employer, UCL Institute of Neurology, for advisory committees and/or consultancy in multiple sclerosis studies from BayerSchering, Biogen Idec, GlaxoSmithKline, and Novartis. He has received research grant support through his employer for performing central MRI analysis for multiple sclerosis trials from Biogen Idec, GlaxoSmithKline, and Novartis. L. Kappos has served as a principal investigator and member or chair of planning and steering committees or advisory boards in corporate-sponsored clinical trials in multiple sclerosis and other neurological diseases. Sponsoring companies for these trials include Acorda Therapeutics, Actelion Pharmaceuticals, Allozyne, BaroFold, Bayer Health Care, BayerSchering Pharma, Bayhill, Biogen Idec, Boehringer-Ingelheim, Eisai, Elan, Genmab, GlaxoSmithKline, Merck-Serono, MediciNova, Novartis, Sanofi-Aventis, Santhera Pharmaceuticals, Shire, Roche, Teva, UCB, Wyeth, and others. He has lectured at medical conferences or in public on various aspects of the diagnosis and management of multiple sclerosis; in many cases these lectures have been sponsored by nonrestricted educational grants from one or another of the above-listed companies. Honoraria and other payments for all these activities have been exclusively used for funding research of his department. Research and the clinical operations (nursing and patient care services) of the MS Center in Basel have been supported by nonrestricted grants from one or more of these companies and by grants from the Swiss MS Society, the Swiss National Research Foundation, the European Union, and the Gianni Rubatto, Novartis, and Roche Research Foundations. R. Gold has served as a speaker or consultant for and received scientific grant support from BayerSchering, Biogen Idec, 
Merck-Serono, Novartis, and Teva. E. Havrdova has received honoraria for lecturing and consulting from Bayer Health Care, Biogen Idec, Genzyme, Merck-Serono, Novartis, Sanofi-Aventis, and Teva. She has received funding for clinical trials and served on advisory boards for Actelion, Bayer Health Care, Biogen Idec, Genzyme, GlaxoSmithKline, Merck-Serono, Novartis, SanofiAventis, and Teva. V. Limmroth has received research support and honoraria for consultancy from Antisense Therapeutics, Bayer, Biogen Idec, GlaxoSmithKline, Merck-Serono, MSD, Pfizer, SanofiAventis, and Teva. C.H. Polman has received consulting fees from Actelion, Antisense Therapeutics, BayerSchering, Biogen Idec, GlaxoSmithKline, Merck-Serono, Novartis, Roche, Teva, and UCB; lecture fees from Biogen Idec, Novartis, Schering AG, and Teva; and grant support from BayerSchering, Biogen Idec, GlaxoSmithKline, Merck-Serono, Novartis, Teva, and UCB. K. Schmierer received research support from Biogen Idec to perform the MRI analysis of the phase $2 b$ trial of BG-12. He has received honoraria for speaking from Merck-Serono, Novartis, and Sanofi-Aventis. T.A. Yousry has served on a scientific advisory board for UCB; received honoraria and funding for travel for serving on scientific boards for Biogen Idec; and received research support from Biogen Idec, GlaxoSmithKline, Novartis, the NIHR UCLH Comprehensive Biomedical Research Centre, the MS Society of Great Britain and Northern Ireland, the MRC, and the Wellcome Trust. He serves on the editorial board for European Radiology. M. Eraksoy serves on the medical advisory board for Biogen Idec. E. Meluzinova declares no conflicts of interest. M. Dufek has served as a subinvestigator for a clinical trial for Biogen Idec (109MS301). M. Yang, K. Dawson, and G.N. O'Neill are employees of and have equity interest in Biogen Idec.

\section{References}

1. Schilling S, Goelz S, Linker R, Luehder F, Gold R (2006) Fumaric acid esters are effective in chronic experimental autoimmune encephalomyelitis and suppress macrophage infiltration. Clin Exp Immunol 145:101-107

2. Wierinckx A, Brevé J, Mercier D, Schultzberg M, Drukarch B, Van Dam AM (2005) Detoxification enzyme inducers modify cytokine production in rat mixed glial cells. J Neuroimmunol 166:132-143

3. Lukashev M, Zeng W, Goelz S, Lee D, Linker R, Gold R et al (2007) Activation of Nrf2 and modulation of disease progression in EAE models by BG00012 (dimethyl fumarate) suggests a novel mechanism of action combining anti-inflammatory and neuroprotective modalities [abstract]. Mult Scler 13(suppl 2): S149

4. Itoh K, Chiba T, Takahashi S, Ishii T, Igarashi K, Katoh Y et al (1997) An Nrf2/small Maf heterodimer mediates the induction of phase II detoxifying enzyme genes through antioxidant response elements. Biochem Biophys Res Commun 236:313-322

5. Venugopal R, Jaiswal AK (1998) Nrf2 and Nrf1 in association with Jun proteins regulate antioxidant response element-mediated expression and coordinated induction of genes encoding detoxifying enzymes. Oncogene 17:3145-3156

6. Chen XL, Dodd G, Thomas S et al (2006) Activation of Nrf2/ ARE pathway protects endothelial cells from oxidant injury and inhibits inflammatory gene expression. Am J Physiol Heart Circ Physiol 290:H1862-H1870

7. Hubbs AF, Benkovic A, Miller DB, O'Callaghan JP, Battelli L, Schwegler-Berry D et al (2007) Vacuolar leukoencephalopathy with widespread astrogliosis in mice lacking transcription factor Nrf2. Am J Pathol 170:2068-2076

8. Kappos L, Gold R, Miller DH, Macmanus DG, Havrdova E, Limmroth V et al (2008) Efficacy and safety of oral fumarate in patients with relapsing-remitting multiple sclerosis: a multicentre, randomised, double-blind, placebo-controlled phase IIb study. Lancet 372:1463-1472

9. van Waesberghe $\mathrm{JH}$, van Walderveen MA, Castelijns JA, Scheltens P, Lycklama à Nijeholt GJ, Polman CH et al (1998) Patterns of lesion development in multiple sclerosis: longitudinal observations with T1-weighted spin-echo and magnetization transfer MR. AJNR Am J Neuroradiol 19:675-683

10. Brück W, Bitsch A, Kolenda H, Brück Y, Stiefel M, Lassmann H (1997) Inflammatory central nervous system demyelination: correlation of magnetic resonance imaging findings with lesion pathology. Ann Neurol 42:783-793

11. McDonald WI, Compston A, Edan G, Goodkin D, Hartung HP, Lublin FD et al (2001) Recommended diagnostic criteria for multiple sclerosis: guidelines from the International Panel on the Diagnosis of Multiple Sclerosis. Ann Neurol 50:121-127

12. Kurtzke JF (1983) Rating neurologic impairment in multiple sclerosis: an expanded disability status scale (EDSS). Neurology 33:1444-1452

13. Brex PA, Molyneux PD, Smiddy P, Barkhof F, Filippi M, Yousry TA, European Study Group on Interferon beta-1b in secondary progressive MS et al (2001) The effect of IFNbeta-1b on the evolution of enhancing lesions in secondary progressive MS. Neurology 57:2185-2190

14. Dalton CM, Miszkiel KA, Barker GJ, MacManus DG, Pepple TI, Panzara $M$ et al (2004) Effect of natalizumab on conversion of gadolinium enhancing lesions to $\mathrm{T} 1$ hypointense lesions in relapsing multiple sclerosis. J Neurol 251:407-413

15. Katz D, Taubenberger JK, Cannella B, McFarlin DE, Raine CS, McFarland HF et al (1993) Correlation between magnetic resonance imaging findings and lesion development in chronic, active multiple sclerosis. Ann Neurol 34:661-669

16. Schmierer K, Scaravilli F, Altmann DR, Barker GJ, Miller DH (2004) Magnetization transfer ratio and myelin in postmortem multiple sclerosis brain. Ann Neurol 56:407-415

17. van Walderveen MAA, Lycklama à Nijeholt GJ, Adèr J, Jongen PJ, Polman CH, Castelijns JA et al (2001) Hypointense lesions on T1-weighted spin-echo magnetic resonance imaging: relation to clinical characteristics in subgroups of patients with multiple sclerosis. Arch Neurol 58:76-81

18. van Walderveen MAA, Barkhof F, Pouwels PJW, van Schijndel RA, Polman CH, Castelijns JA et al (1999) Neuronal damage in T1-hypointense multiple sclerosis lesions demonstrated in vivo using proton magnetic resonance spectroscopy. Ann Neurol 46:79-87

19. Filippi M, Rovaris M, Rocca MA, Sormani MP, Wolinsky JS, Comi G, European/Canadian Glatiramer Acetate Study Group (2001) Glatiramer acetate reduces the proportion of new MS lesions evolving into "black holes". Neurology 57:731-733

20. Cadavid D, Cheriyan J, Skurnick J, Lincoln JA, Wolansky LJ, Cook SD (2009) New acute and chronic black holes in patients with multiple sclerosis randomized to interferon beta- $1 \mathrm{~b}$ or glatiramer acetate. J Neurol Neurosurg Psychiatry 80:1337-1343

21. Schimrigk S, Brune N, Hellwig K, Lukas C, Bellenberg B, Rieks $M$ et al (2006) Oral fumaric acid esters for the treatment of active multiple sclerosis: an open-label, baseline-controlled pilot study. Eur J Neurol 13:604-610

22. Vargas MR, Pehar M, Cassina P, Martínez-Palma L, Thompson JA, Beckman JS et al (2005) Fibroblast growth factor-1 induces heme oxygenase-1 via nuclear factor erythroid 2-related factor 2 (Nrf2) in spinal chord astrocytes. J Biol Chem 280:25571-25579 
23. Li J, Johnson D, Calkins M, Wright L, Svendsen C, Johnson J (2005) Stabilization of Nrf2 by tBHQ confers protection against oxidative stress-induced cell death in human neural stem cells. Toxicol Sci 83:313-328

24. Satoh T, Okamato S-I, Cui J, Watanabe Y, Furuta K, Suzuki M et al (2006) Activation of the Keap1/Nrf2 pathway for neuroprotection by electrophillic [sic] phase II inducers. Proc Natl Acad Sci USA 103:768-773
25. Zhao J, Moore AN, Redell JB, Dash PK (2007) Enhancing expression of Nrf2-driven genes protects the blood-brain barrier after brain injury. J Neurosci 27:10240-10248

26. Van den Elskamp I, Lembcke J, Dattola V, Beckmann K, Pohl C, Hong W et al (2008) Persistent T1 hypointensity as an MRI marker for treatment efficacy in multiple sclerosis. Mult Scler 14:764-769 